\title{
The Effect of Type of Feedback on Intrinsic Motivation and Learning of Volleyball Jump Serve in Students with Different Levels of Neuroticism
}

\author{
Rokhsareh Badami* \\ Department of Physical Education and Sports Sciences, Isfahan (Khorasgan) Branch, Islamic Azad \\ University, Isfahan, Iran.
}

Submitted 06 November 2019; Accepted in final form 06 March 2020.

\begin{abstract}
Background. Several researchers have studied the effects of type of feedback on learning motor skills, but there are few studies on the interaction between personality traits and the type of feedback. Objectives. This study aimed at investigating the effect of type of feedback on intrinsic motivation and learning volleyball jump serve in students with neuroticism. Methods. A total of 59 female-16-17-year-old students were classified into 4 groups based on their psycho inventorial neurosis and type of feedback. Research tools included NEO five factors and intrinsic motivation inventories. The participants' goal was volleyball jump serving. In the acquisition phase, the participants performed 96 volleyball jump serves in four blocks of trials of 24 . The retention test was conducted two weeks after the acquisition phase. Before and after the acquisition phase, participants completed the intrinsic motivation inventory. Results. The type of feedback had an effect on acquisition ( $\mathrm{p}=0.33)$, retention $(\mathrm{p}<0.001)$, and intrinsic motivation $(\mathrm{p}<0.001)$, and the positive normative feedback group had better intrinsic motivation and better learning than the negative normative feedback group. The effect of personality type on acquisition and intrinsic motivation was significant, and highly neurotic students (Score 81 to 105) had lower scores on acquisition phase and lower intrinsic motivation. However, the effect of personality type on retention scores was not significant. Conclusion. Positive normative feedback for learning of the volleyball jump serve is better than negative normative feedback for beginners.
\end{abstract}

KEYWORDS: Feedback, Personality, Neuroticism, Motivation, Learning.

\section{INTRODUCTION}

For many years, researchers have been trying to find ways to increase motor learning and have proposed theories and models about the effect of training variables on motor learning. The Challenge-Point Framework has been recently received by experts. Gadagnoli \& Lee proposed a challenge-point framework for the conceptualization of the effect of training variables on motor learning (first, background interference, and then, feedback on practice awareness) (1). Based on the challenge-point framework, motor learning is maximized when is faced with the optimal level of challenge during a motor skill acquisition process. In the context of the challenge-point framework, information is seen as a challenge for the implementer. If the imposed challenge is too easy or too difficult, learning will be reduced. Accordingly, the level of challenge varies with the nominal difficulty of the task (2), difficulty of performance $(2,3)$ learning skill level, or feedback (1). Research studies conducted on the added feedback over

*. Corresponding Author:

Rokhsareh Badami, Associate Professor

E-mail: rokhsareh.badami@khuisf.ac.ir 
recent years, have shown that motor skills learning increases as the learner's hope for successful implementation of the skill increases. In these studies, by giving feedback on successful trials and ignoring unsuccessful trials of beginners, the learners' hope for learning was increased and subsequently improved (4). Additionally, other studies have used positive normative feedback. In the present study, the learners were informed of their real performance as well as the group's false performance. When feedback points to a better performance than the group average, the sense of competence, expectancy, learning, and interest in the continued participation of sports was increased (5-7).

Perhaps the reason of this increase was because the beginners were confronted with something less challenging. Based on the challenge-point, beginners should be faced with a less challenging challenge, and the challenge is increased for them with the automation of the skill (1). In their research study, Chauvel, Wulf, \& Maquestiaux (8) stated that pointing out correct movements and ignoring mistakes, as well as asserting the notion that a person's skill was more than the average of the group and the illusion of seeing the hole bigger would probably increase the hopes of the participants and simplify the task, and as a result, lessen the challenge for the beginners.

Based on the challenge-point framework, nominal task difficulty also affected learning. In this connection, Witt, Linkenauger, \& Proffitt used visual illusions to change the perception of the task difficulty, and showed a golf hole larger or smaller than normal using visual illusions (9). The findings showed that the illusion of seeing the golf hole bigger had a positive effect on performance. Nominal difficulty refers to a person's perception of a simple or difficult task. If the person's perception of the task is simple, the challenge can be increased when they are learning motor skills by changing information. But if one's perception of the task is tough, it is better to be cautious about increasing the challenge. The nominal difficulty of the task seems to be changed depending on the individual differences in perception (1). In other words, it is possible that two beginners, under the same conditions, have a different perception of the difficulty of the task depending on their past experiences. The reason is because the perception of different individuals differs in a completely same situation and depends on their experiences and personality traits (10). On the other hand, the type of feedback may affect the challenge. Perhaps the effect of the type of feedback on learning depends on the personal traits of individuals (11). In other words, a difference in personality may lead to different reactions to a similar situation. Therefore, individuals with different personality traits are likely to benefit from different feedbacks (12). One of the personality traits that researchers are interested in is the neuroticism trait of personality traits. Individuals with neuroticism are those who react very quickly to the pressure (13). Neurotic individuals are emotionally unstable and more likely to experience emotions such as anxiety, anger, guilt, and clinical depression than others. These individuals are very quickly emotionally evoked and very slowly return to normal conditions, and are more prepared affected by negative feedback (14). Accordingly, perhaps, those with neuroticism may be more affected by anxiety status, such as negative feedback on performance. Especially when people have low mental preparation $(15,16)$. In this context, some studies have examined the role of trait anxiety in relation to other learning variables. For example, in an attempt to study the association between trait anxiety and the frequency of self-control feedback in the motor skill acquisition phase, Bokums, Cassio, Meira, Jaqueline, \& Neiva concluded that participants who had higher trait anxiety requested more feedback (17).

A review of the related literature shows that few studies have been conducted on the interaction between personality traits and the type of feedbacks. Investigating the interaction of these two variables is likely to provide useful information on motor learning. Additionally, based on the hypothesis of the challenge-point framework, learning is directly related to the level of challenge created for the individual during the task (18). The question arises as to whether it is possible to maintain the level of challenge created for them by providing feedback tailored to the personality traits of the participants, and provide the optimal conditions for acquiring and learning the skills. Based on the hypothesis challenge point, it was anticipated that those with neuroticism would have optimized positive normative feedback and those who were emotionally stable would have optimized negative normative feedback because according to the hypothesis of challenge point, in order to be 
better learners, they have to face an optimal challenge (1). Based on the hypothesis, the purpose of this study was to determine the effect of the type of feedback and the type of personality (level of neuroticism) on volleyball serves.

\section{MATERIALS AND METHODS}

Participants. The statistical population of this study consisted of 621 female high school students with average age of $17(\mathrm{SD}=0.56)$ years in the Jey Isfahan region. In order to determine the subjects at different levels of neuroticism, a NEO-FFI questionnaire (13) was distributed among them. Those who had low neuroticism (Score 43 to 59) and high neuroticism scores (Score 81 to 105) were selected. In the next phase, of the aforementioned students, those who were familiar with volleyball hammer serve and did not attend volleyball classes outside school hours over the last two months were selected. In these conditions, 26 individuals were identified as high neuroticism individuals and 33 as low neuroticism individuals. Each of the groups with high level of neuroticism and low level of neuroticism were randomly placed into one of the positive or negative normative feedback groups.

Apparatus, Task, and Procedure. Participants were divided into four groups: Neuroticism with high level - positive normative feedback, neuroticism with high level - negative normative feedback, neuroticism with low level positive normative feedback, and neuroticism with low level - negative normative feedback.

In this research, the NEO-FFI questionnaire and intrinsic motivation inventory were used to assess the subject's personality and the subject's intrinsic motivation, respectively. An individual test was used to measure the value of the volleyball serve.

NEO-FFI. This questionnaire is a shortened form of the NEO-PI questionnaire developed by McCrae \& Costa (13) to obtain a concise and precise measure of the five fundamental factors of personality. The questionnaire embraces 5 fields (neuroticism $(\mathrm{N})$, extraversion (E), openness to experience (O), agreeableness (A) and conscientiousness (C)) each of which are measured with 12 closed questions. This questionnaire items are scored based on a five-point Likert scale ranging from 0 to 5 (I strongly disagree (0), disagree, no opinion, agree, and strongly agree (5).

In a study conducted to revise the NEO-FFI questionnaire on 450 students (253 females, 197 male) ranged between 8 and 18 years' old, reported the cronbach's alpha coefficient for the five factors $\mathrm{C}, \mathrm{A}, \mathrm{O}, \mathrm{E}$, and $\mathrm{N}$ to be $0.64,0.73$,
$0.70,0.72$, and 0.70 respectively. Moreover, testretest correlation coefficient within a one-month interval range showed from 0.85 for openness to 0.92 for conscientiousness (19).

Intrinsic Motivation Inventory (IMI). This 45-item inventory comprised of 7 subscales of interest/enjoyment, perceived competence, effort/importance, tension / pressure stress, choice of perception, value / usefulness, and the establishment of communication. For scoring, the reverse items were first scored. Then the total scores for each of the subscales were calculated. The spectrum of responses was based on a 7-point Likert scale of "1" completely incorrect, to "7" completely correct. Items have an acceptable factual validity, and the construct validity of this inventory was confirmed in the McAleague, Duncan, and Tamen study (20). In previous studies, different versions of this inventory with different subscales and the number of different have been used. A nine-item questionnaire consisting of the interest/enjoyment, perceived competence, and effort/importance subscales of the IMI was used in this study (4). The reliability coefficient of each of the three factors of this inventory for interest/enjoyment, perceived competence and effort/importance were calculated using the Cronbach's alpha method to be $0.9,0.8$, and 0.81 respectively.

AAHPERD Volleyball Serve Test. The AAHPERD Volleyball Serve Test is a research tool used to measure the accuracy and precision of performing the skill of volleyball serving. The validity and reliability of this test has been confirmed (21). The rating of each serve in this test was equal to the area in which the ball landed (Figure 1). The zone at the end of the court (one and a half meters wide), the two side zones (one and a half meters long), the enclosed area between the zones four and three near the middle line (four and a half meters from the middle line), and the rest of the court assigned 4, 3, 1 , and 2 points to themselves, respectively. According to the rules of FIVB, to perform the test, a person is required to perform the serve from behind the end line anywhere they want to the other side of the court.

Procedure. At the beginning of the acquisition phase, the coach taught the volleyball jump serve to the participants. After training, participants were given the opportunity to do ten tries and ask questions if they had any. After that, the real trials began. The acquisition phase consisted of six sessions, each of which consisted of four blocks of four trials. In other 
words, during the acquisition phase, 24 blocks of trials were made in trials of fours ( 96 trials). Between each attempt, 5 to 10 seconds, and between each round of trials, 5 minutes were considered as rest period. Participants would receive feedback after each round of trials according to their group. In this way, the participants of the positive normative feedback group became aware of their average scores after each of the four trials, and average group scores were less than their average scores by $10 \%$. After each of the four trials, the participants of the negative normative feedback group became aware of their average rating and average group scores were higher than their average scores by $10 \%$. The retention test was conducted two weeks after the acquisition phase. Participants made ten trials without feedback. The intrinsic motivation inventory was completed by the participants before and after the acquisition phase.

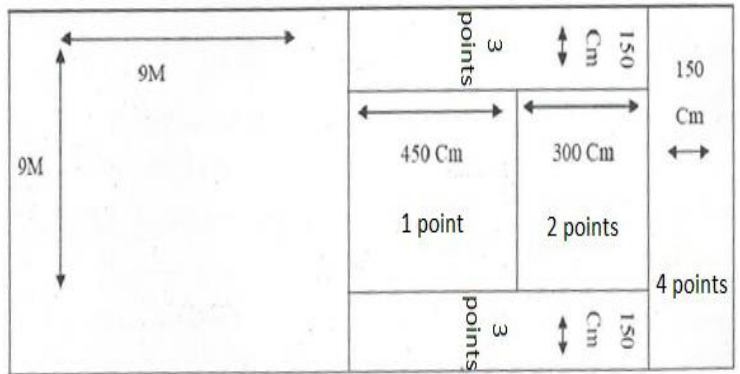

Figure 1. AAHPERD Volleyball Serve Test

Data Analysis. Serve accuracy scores were analyzed in a 2 (feedback: positive, negative) $\times 2$ (personality: low neuroticism, high neuroticism) $\times 24$ (blocks of 4 trials) analysis of variance (ANOVA) with repeated measures on the last factor for the practice phase. In addition, serve accuracy scores in retention test were analyzed in a 2 (feedback: positive, negative) $\times 2$ (personality: low neuroticism, high neuroticism) ANOVA. Finally, motivation scores were analyzed in a 2 (feedback: positive, negative) $\times 2$ (personality: low neuroticism, high neuroticism) $\times 2$ (session: pretest, posttest) ANOVA.

\section{RESULTS}

The means and standard deviations for the serve accuracy scores are shown in Table 1. Based on the results of Table 1, in the acquisition phase, the lowest average score for the negative normative feedback group was for individuals with low-neurotic personality. The highest average score for the positive feedback group was related to those with stable personality.
In the acquisition phase, results of repeated measure ANOVA in between group analysis revealed a significant main effect of personality $\left(\mathrm{F}_{1.50}=4.268, \mathrm{p}=0.044, \eta^{2}=0.079\right)$ and feedback $\left(\mathrm{F}_{1.50}=4.831, \mathrm{p}=0.033, \eta^{2}=0.088\right)$. But there was no significant interaction between personality and feedback $\quad\left(\mathrm{F}_{1.50}=0.082, \quad \mathrm{p}=0.776, \quad \eta^{2}=0.002\right)$. Bonferroni post hoc test showed that the mean score of positive feedback group and low neuroticism group was significantly higher than negative feedback groups and high neuroticism groups.

Also, in within group analysis, there were significant effects of block $\left(\mathrm{F}_{15.2,760.8}=5.259\right.$, $\mathrm{p}<0.001, \eta^{2}=0.095$ ), interaction between block and personality $\left(\mathrm{F}_{15.2,760.8}=1.693, \mathrm{p}=0.046\right.$, $\eta^{2}=0.033$ ), and interaction between block and feedback $\left(\mathrm{F}_{15.2,760.8}=2.477, \mathrm{p}=0.001, \eta^{2}=0.047\right)$. But interaction between block, personality and feedback was not significant $\left(\mathrm{F}_{15.2,760.8}=1.028\right.$, $\mathrm{p}=0.423, \eta^{2}=0.020$ ).

In the retention test, the average score of the participants with stable personality in both positive and negative normative groups was more than that of the participants who had neuroticism.

Results of $2 \times 2$ ANOVA revealed significant main effect of feedback $\left(\mathrm{F}_{1.50}=21.800, \mathrm{p}<0.001\right.$, $\left.\eta^{2}=0.304\right)$. But there was no significant effect of personality $\left(\mathrm{F}_{1.50}=2.752, \mathrm{p}=0.103, \eta^{2}=0.052\right)$ and interaction between personality and feedback $\left(\mathrm{F}_{1.50}=0.514, \mathrm{p}=0.477, \eta^{2}=0.010\right)$.

Results of Bonferroni post hoc test showed that the mean score of positive feedback groups was significantly higher than that of negative feedback groups in retention test in serve accuracy scores.

In Intrinsic Motivation, Results of $2 \times 2$ ANCOVA revealed that controlling for the pretest score, the effects of personality $\left(\mathrm{F}_{1.49}=19.88\right.$, $\left.\mathrm{p}<0.001, \quad \eta^{2}=0.289\right), \quad$ feedback $\quad\left(\mathrm{F}_{1.49}=337.21\right.$, $\left.\mathrm{p}<0.001, \eta^{2}=0.873\right)$ and interaction between them $\left(\mathrm{F}_{1.49}=13.78, \mathrm{p}<0.001, \eta^{2}=0.220\right)$ were statistically significant at the 0.05. Results of Bonferroni post hoc test for interaction effect showed that in positive normative feedback group, there was no significant different between high and low neuroticism $(\mathrm{p}=0.556)$, but in negative normative feedback group, the mean score of low neuroticisms was significantly higher than that of high neuroticism $(\mathrm{p}<0.001)$. Also, in both of low and high neuroticisms persons, the mean score of positive normative feedback group was significantly higher than that of negative normative feedback group $(\mathrm{p}<0.001)$. 
Table 1. Means and Standard Deviations for Serve Accuracy Scores in Practice

\begin{tabular}{lcccc}
\hline Group & \multicolumn{2}{c}{ Positive Normative Feedback } & \multicolumn{2}{c}{ Negative Normative Feedback } \\
& Low Level Neuroticism & High Level Neuroticism & Low Levels Neuroticism & High Levels Neuroticism \\
\hline 1 Block & $2.31 \pm 0.53$ & $2.33 \pm 0.81$ & $2.06 \pm 0.75$ & $1.77 \pm 0.72$ \\
2 Block & $2.29 \pm 0.49$ & $1.83 \pm 0.46$ & $2.02 \pm 0.66$ & $1.75 \pm 0.66$ \\
3 Block & $2.40 \pm 0.93$ & $1.94 \pm 1.05$ & $2.13 \pm 1.20$ & $1.85 \pm 1.27$ \\
4 Block & $1.98 \pm 0.53$ & $2.08 \pm 0.70$ & $1.77 \pm 0.86$ & $1.69 \pm 0.90$ \\
5 Block & $2.23 \pm 0.77$ & $1.83 \pm 0.86$ & $1.97 \pm 0.77$ & $1.69 \pm 0.87$ \\
6 Block & $2.25 \pm 0.83$ & $2.19 \pm 0.87$ & $2.42 \pm 0.85$ & $2.19 \pm 1.15$ \\
7 Block & $2.29 \pm 0.96$ & $2.56 \pm 0.92$ & $2.25 \pm 0.71$ & $2.33 \pm 0.79$ \\
8 Block & $2.81 \pm 0.76$ & $2.63 \pm 0.72$ & $2.41 \pm 0.89$ & $2.21 \pm 0.76$ \\
9 Block & $2.67 \pm 0.73$ & $2.33 \pm 0.68$ & $2.61 \pm 1.04$ & $2.23 \pm 0.98$ \\
10 Block & $3.06 \pm 0.74$ & $2.58 \pm 0.89$ & $2.36 \pm 0.90$ & $.56 \pm 0.63$ \\
11 Block & $2.83 \pm 0.57$ & $2.10 \pm 1.00$ & $2.09 \pm 0.93$ & $1.71 \pm 1.12$ \\
12 Block & $2.58 \pm .55$ & $2.19 \pm 0.82$ & $2.30 \pm 1.03$ & $2.04 \pm 1.11$ \\
13 Block & $2.88 \pm 0.53$ & $2.46 \pm 0.76$ & $2.70 \pm 1.00$ & $2.37 \pm 0.84$ \\
14 Block & $2.83 \pm 0.49$ & $2.48 \pm 0.71$ & $2.34 \pm 1.07$ & $2.15 \pm 0.90$ \\
15 Block & $2.42 \pm 0.66$ & $2.62 \pm 0.71$ & $2.48 \pm 1.11$ & $1.96 \pm 1.26$ \\
16 Block & $2.92 \pm 0.44$ & $2.60 \pm 0.52$ & $2.53 \pm 0.88$ & $2.06 \pm 0.99$ \\
17 Block & $2.79 \pm 0.56$ & $2.52 \pm 0.75$ & $2.58 \pm 0.90$ & $2.37 \pm 0.96$ \\
18 Block & $2.69 \pm 0.71$ & $2.35 \pm 0.67$ & $2.36 \pm 0.88$ & $1.90 \pm 1.10$ \\
19 Block & $2.52 \pm 0.78$ & $1.88 \pm 0.92$ & $2.13 \pm 0.88$ & $1.77 \pm 1.09$ \\
20 Block & $2.73 \pm 0.47$ & $2.46 \pm 0.80$ & $2.23 \pm 0.93$ & $2.10 \pm 0.97$ \\
21 Block & $2.71 \pm 0.45$ & $2.31 \pm 0.80$ & $2.72 \pm 0.83$ & $2.35 \pm 0.78$ \\
22 Block & $2.79 \pm 0.58$ & $2.38 \pm 0.58$ & $2.36 \pm 1.08$ & $2.25 \pm 0.84$ \\
23 Block & $2.52 \pm 0.58$ & $2.56 \pm 0.74$ & $2.34 \pm 0.92$ & $1.94 \pm 1.16$ \\
24 Block & $2.81 \pm 0.56$ & $2.73 \pm 0.69$ & $2.30 \pm 0.98$ & $1.77 \pm 1.02$ \\
Retention test & $2.89 \pm 0.7$ & $2.65 \pm 0.85$ & $1.89 \pm 1.07$ & $1.29 \pm 1.01$ \\
Motivation pretest & $50.33 \pm 7.10$ & $46.54 \pm 8.9$ & $47.81 \pm 8.12$ & $43.62 \pm 9.29$ \\
Motivation & $55.92 \pm 5.76$ & $52.54 \pm 6.77$ & $39.06 \pm 6.84$ & $27.85 \pm 6.95$ \\
posttest & & & & \\
\hline
\end{tabular}

The data in the table written as mean \pm SD.

Table 2. Results of Repeated Measure ANOVA in in Acquisition Phase

\begin{tabular}{lcccccc}
\hline & Sum of Square & Df & Mean Square & F & Sig. & $\boldsymbol{\eta}^{\mathbf{2}}$ \\
\hline Between group & & & & & \\
$\quad$ Personality & 30.612 & 1 & 30.612 & 4.268 & 0.044 & 0.079 \\
Feedback & 34.651 & 1 & 34.651 & 4.831 & 0.033 & 0.088 \\
Feedback* Personality & 0.590 & 1 & 0.590 & 0.082 & 0.776 & 0.002 \\
Error & 358.655 & 50 & 7.173 & & & \\
Within group & & & & & \\
Block & 53.483 & 15.217 & 3.515 & 5.259 & $<0.001$ & 0.095 \\
Block* personality & 17.213 & 15.217 & 1.131 & 1.693 & 0.046 & 0.033 \\
Block* feedback & 25.188 & 15.217 & 1.655 & 2.477 & 0.001 & 0.047 \\
Block* Feedback* Personality & 10.455 & 15.217 & 0.687 & 1.028 & 0.423 & 0.020 \\
Error & 508.455 & 760.833 & 0.668 & & & \\
\hline
\end{tabular}

Table 3. Mean and Standard Deviation of Volleyball Service and Results of Two Way ANOVA Score in Retention Test with Positive and

\begin{tabular}{|c|c|c|c|c|c|c|}
\hline \multirow{3}{*}{ Levels Neuroticism } & \multirow{3}{*}{$\mathbf{N}$} & \multirow{3}{*}{ M } & \multirow{3}{*}{ SD } & \multirow{2}{*}{\multicolumn{3}{|c|}{ Results of $2 \times 2$ ANOVA, $p\left(\eta^{2}\right)$}} \\
\hline & & & & & & \\
\hline & & & & Personality & Feedback & Feedback* Personality \\
\hline & & & & $0.103,(0.052)$ & $<0.001(0.304)$ & $477,(0.010)$ \\
\hline \multicolumn{7}{|l|}{ Positive } \\
\hline High & 12 & 2.89 & 0.70 & & & \\
\hline Low & 13 & 2.65 & 0.80 & & & \\
\hline \multicolumn{7}{|l|}{ Negative } \\
\hline High & 16 & 1.89 & 1.07 & & & \\
\hline Low & 13 & 1.29 & 1.01 & & & \\
\hline
\end{tabular}

In interest subscale, results of $2 \times 2$ ANCOVA revealed that controlling for the pretest score, the effects of personality $\left(\mathrm{F}_{1.49}=5.70, \quad \mathrm{p}=0.021\right.$, $\left.\eta^{2}=0.104\right)$ and feedback $\left(\mathrm{F}_{1.49}=110.259, \mathrm{p}<0.001\right.$, $\eta^{2}=0.693$ ) were statistically significant at the 0.05 . But there was no significant effect of interaction between them $\left(\mathrm{F}_{1.49}=2.18, \mathrm{p}=0.146, \eta^{2}=0.043\right)$. Results of Bonferroni post hoc test showed that the mean score of positive normative feedback group was significantly higher than that of negative normative feedback group in both low $(\mathrm{p}=0.021)$ and high $(\mathrm{p}<0.001)$ neuroticism persons. 
In perceived competence subscale, Results of $2 \times 2$ ANCOVA revealed that controlling for the pretest score, the effects of personality $\left(F_{1,49}=18.35, \quad p<0.001, \quad \eta^{2}=0.272\right), \quad$ feedback $\left(\mathrm{F}_{1,49}=178.18, \mathrm{p}<0.001, \eta^{2}=0.784\right)$ and interaction between them $\left(\mathrm{F}_{1,49}=20.06, \mathrm{p}<0.001, \eta^{2}=0.290\right)$ were statistically significant at the 0.05 . Results of Bonferroni post hoc test for interaction effect showed that in positive normative feedback group, there was no significant different between high and low neuroticism $(\mathrm{p}=0.998)$, but in negative normative feedback group, the mean score of low neuroticisms was significantly higher than that of high neuroticism $(\mathrm{p}<0.001)$. Also, in both of low and high neuroticisms persons, the mean score of positive normative feedback group was significantly higher than that of negative normative feedback group $(p<0.001)$.

In effort subscales, Results of $2 \times 2$ ANCOVA revealed that controlling for the pretest score, the effects of personality $\left(\mathrm{F}_{1,49}=5.82, \mathrm{p}=0.020\right.$, $\left.\eta^{2}=0.106\right)$ and feedback $\left(F_{1,49}=175.57, p<0.001\right.$, $\eta^{2}=0.782$ ) were statistically significant at the 0.05 . But there was no significant effect of interaction between them $\left(\mathrm{F}_{1,49}=3.64, \mathrm{p}=0.062, \eta^{2}=0.069\right)$. Results of Bonferroni post hoc test showed that, the mean score of positive normative feedback group was significantly higher than that of negative normative feedback group in both low $(\mathrm{p}=0.020)$ and high $(\mathrm{p}<0.001)$ neuroticisms persons.

Table 4. Mean and Standard Deviation of Intrinsic Motivation and Its Subscales in Pretest and Posttest with Results of Two Way

\begin{tabular}{|c|c|c|c|c|c|}
\hline \multirow{3}{*}{ Levels Neuroticism } & \multirow{3}{*}{ Pretest } & \multirow{3}{*}{ Posttest } & \multirow{2}{*}{\multicolumn{3}{|c|}{ Results of ANCOVA $p\left(\eta^{2}\right)$}} \\
\hline & & & & & \\
\hline & & & Personality & Feedback & Feedback* Personality \\
\hline Interest & & & $0.021,(0.104)$ & $<0.001(0.693)$ & $.146,(0.043)$ \\
\hline \multicolumn{6}{|l|}{ Positive } \\
\hline High & $17.25 \pm 2.93$ & $19.08 \pm 1.98$ & & & \\
\hline Low & $15.54 \pm 2.70$ & $17.46 \pm 2.93$ & & & \\
\hline \multicolumn{6}{|l|}{ Negative } \\
\hline High & $15.38 \pm 3.05$ & $12.38 \pm 3.34$ & & & \\
\hline Low & $13.77 \pm 4.34$ & $9.08 \pm 3.09$ & & & \\
\hline Perceived competence & & & $<0.001(0.272)$ & $<0.001(0.784)$ & $<0.001(0.290)$ \\
\hline \multicolumn{6}{|l|}{ Positive } \\
\hline High & $17.08 \pm 3.06$ & $18.17 \pm 2.98$ & & & \\
\hline Low & $14.92 \pm 5.04$ & $16.62 \pm 4.41$ & & & \\
\hline \multicolumn{6}{|l|}{ Negative } \\
\hline High & $17.00 \pm 3.41$ & $14.31 \pm 2.33$ & & & \\
\hline Low & $14.62 \pm 3.73$ & $8.77 \pm 2.80$ & & & \\
\hline Effort & & & $0.020,(0.106)$ & $<0.001(0.782)$ & $0.062,(0.069)$ \\
\hline \multicolumn{6}{|l|}{ Positive } \\
\hline High & $16.00 \pm 3.07$ & $18.67 \pm 2.39$ & & & \\
\hline Low & $16.08 \pm 3.55$ & $18.46 \pm 2.50$ & & & \\
\hline \multicolumn{6}{|l|}{ Negative } \\
\hline High & $15.44 \pm 2.78$ & $12.38 \pm 2.87$ & & & \\
\hline Low & $15.23 \pm 3.79$ & $10.00 \pm 4.00$ & & & \\
\hline Intrinsic motivation & & & $<0.001(0.289)$ & $<0.001(0.873)$ & $0.001,(0.220)$ \\
\hline \multicolumn{6}{|l|}{ Positive } \\
\hline High & $50.33 \pm 7.10$ & $55.92 \pm 5.76$ & & & \\
\hline Low & $46.54 \pm 8.90$ & $52.54 \pm 6.77$ & & & \\
\hline \multicolumn{6}{|l|}{ Negative } \\
\hline High & $47.81 \pm 8.16$ & $39.06 \pm 6.84$ & & & \\
\hline Low & $43.62 \pm 9.29$ & $27.85 \pm 6.95$ & & & \\
\hline
\end{tabular}

\section{DISCUSSION AND CONCLUSION}

The findings of this study showed that positive normative feedback was more effective than negative normative feedback on the acquisition and retention test of volleyball serve skills in the groups. These findings were consistent with those obtained by Hutchinson et al. (22), Lewthwaite \& Wulf (23), Wulf et al. (7), and Luciana et al. (24). In the above studies, the better effect of positive normative feedback compared to negative normative feedback was proven in learning to produce force (20), balancing (23), scheduling tasks (7), shooting/throwing tasks in children (24), and volleyball serves (25). The superiority of effect of positive normative feedback to negative normative feedback on learning can be attributed to the increased sense of competence and interest (20), increased intrinsic motivation and increased vitality during exercise (25), increased self-efficacy (20), and increased perceived ability (24). Additionally, Arjmand \& Badami (24) reported that the interest in the continued participation of sports in the positive normative feedback group was higher than the 
negative normative feedback group. In a study, it was also found that improving and increasing hope reduces oxygen consumption and improves running performance (26).

The other finding of this study showed that the level of interest (enjoyment), sense of competence, amount of effort, and intrinsic motivation of the positive normative feedback group was higher than that of the negative normative feedback groups. This finding can be justified by using Seligman's theory, Harter's motivation theory, and the theory of expectation $x$ value.

The lower level of learning and intrinsic motivation in the negative normative feedback group compared to the positive normative feedback can be justified according to Seligman's theory. According to this theory, when the desired consequences are independent from individual voluntary behavior, learned helplessness is created. In other words, learned helplessness is a psychoinventoryical state in which a person feels that environmental events cannot be controlled and cannot be changed by effort. Negative normative feedback groups in the various training sessions seem to perceive the uncontrollability of the situation and consider their efforts to achieve the desired outcome futile. Indeed, the negative normative feedback group consistently received negative feedback. This negative feedback was independent of their efforts, which probably affected their emotional states, the amount of effort, and consequently, the amount of their learning. According to Badhwer (27), the individual in such a situation examines hypotheses to ameliorate the situation, but due to the uncontrollable nature of the events, their cognitive efforts are ineffective. Individuals in this case, experience unstable cognitive fatigue (28), the nature of which is a generalized deterrence of constructive information processing. As the subject's satisfaction with practical programs decreases (29), the individual seeks to reduce cognitive activity by interfering with the attention and inhibition of information processing (26). Similarly, negative normative feedback may interfere with the setting of individual goals, and may cause the individual to target their goals at a lower level (20).

According to Harter's theory of motivation, individuals are motivated to be competent in all areas. In order to satisfy the motivation to compete in an area such as sport, a person seeks to acquire the skill and mastery of sport. An individual's perception of mastering a skill, positive or negative emotions, and motivation changes subsequently. The more the motivation increases, the more the individual is encouraged to make further efforts. On the contrary, if trials are made to perceive failure or rejection, they will result in negative emotions and decreased motivation for competency (30). It seems that in this study, individuals also received negative normative feedback in a situation where their performance was lower than that of the group, and as a result, the person felt unsuccessful, and this negative feeling caused the amount of interest of the negative normative feedback group to be lower than that of the positive normative feedback group. According to the theory of expectation $\mathrm{x}$ value, the tendency to approach an environmental stimulus is the product of the two cognitive structures of performance expectation and value. Performance expectation is the belief of individuals in their ability to perform that behavior and is the value of the expected satisfaction that a person has achieved from that behavior. If performance expectation is only high or if the value is only high, the person's tendency to do that behavior is relatively reduced. In the negative normative feedback group, it seemed that the performance expectation was reduced due to negative feedback. Therefore, the lower interest score of the negative normative feedback group compared to the positive normative feedback group was not unexpected.

Findings of this study showed that the type of personality (different levels of neuroticism) did not have a significant effect on learning (retention test), but the effect of personality type on intrinsic motivation was significant and emotionally stable individuals had higher intrinsic motivation than neurotic ones. This study showed that personality type does not have any effect on the level of learning, which was consistent with those of McKenzie (31) indicating that individuals with neuroticism had lower educational achievement. Perhaps, this occurs due to the different kinds of tasks. In past research, the effect of personality type on academic performance (cognitive function) was investigated, but in this research, the effect of personality type on learning a motor movement was measured. Similarly, most of the previous studies were casual-comparative and did not apply independent variables, but this research was of an experimental type and an independent variable was applied. However, higher levels of 
intrinsic motivation and its subscales (the amount of interest, effort, and enjoyment) in emotionally stable individuals compared to individuals with neuroticism can be justified by the fact that personality traits are mood incentives to reach the goals and in the sense that these traits predispose individuals to different behaviors in certain situations (9).

The other finding of this study showed that the interaction between personality type and type of feedback on learning was not significant. Regarding the fact that emotionally stable individuals have less anxiety, it was assumed that negative feedback with an optimal level of anxiety would lead to better learning in stable individuals. But in both emotionally stable and neurotic individuals, positive normative feedback was better. Perhaps this is related to the Fitts and Posner phases, in which learners go through three cognitive, associative, and autonomous phases. In the cognitive and early phase of association, the level of error is still high. Given that the volleyball jump serving is a difficult task for beginners to learn, the type of challenge may be challenging enough, and because of this, positive normative feedback for both groups would lead to better learning for both of them.

Since positive normative feedback promotes performance, it is suggested in future research to determine the effect of normative feedback on variables such as athletes' attention, concentration and mood. In addition, mental skill is associated with perception (31), so it is suggested that the effect of normative feedback on performance be assessed with respect to the mediating role of mental skills.

\section{APPLICABLE REMARKS}

- Trainers use positive normative feedback to train the volleyball jump serve to create better learning in novice.

- Trainers use positive normative feedback to train the volleyball jump serve to create more intrinsic motivation in novice.

- Trainers should note that neuroticism affects intrinsic motivation.

\section{REFERENCES}

1. Guadagnoli MA, Lee TD. Challenge point: a framework for conceptualizing the effects of various practice conditions in motor learning. J Mot Behav. 2004;36(2):212-224. doi: 10.3200/JMBR.36.2.212224 pmid: 15130871

2. Sanli EA, Lee TD. Nominal and functional task difficulty in skill acquisition: Effects on performance in two tests of transfer. Hum Mov Sci. 2015;41:218-229. doi: 10.1016/j.humov.2015.03.006 pmid: 25846951

3. Cantin N, Ryan J, Polatajko HJ. Impact of task difficulty and motor ability on visual-motor task performance of children with and without developmental coordination disorder. Hum Mov Sci. 2014;34:217-232. doi: 10.1016/j.humov.2014.02.006 pmid: 24709062

4. Badami R, VaezMousavi M, Wulf G, Namazizadeh M. Feedback after good versus poor trials affects intrinsic motivation. Res $Q$ Exerc Sport. 2011;82(2):360-364. doi: 10.1080/02701367.2011.10599765 pmid: 21699117

5. Ávila LTG, Chiviacowsky S, Wulf G, Lewthwaite R. Positive social-comparative feedback enhances motor learning in children. Psychol Sport Exerc. 2012;13(6):849-853. doi: 10.1016/j.psychsport.2012.07.001

6. Gonçalves GS, Cardozo PL, Valentini NC, Chiviacowsky S. Enhancing performance expectancies through positive comparative feedback facilitates the learning of basketball free throw in children. Psychol Sport Exerc. 2018;36:174-177. doi: 10.1016/j.psychsport.2018.03.001

7. Wulf G, Chiviacowsky S, Lewthwaite R. Normative feedback effects on learning a timing task. Res $Q$ Exerc Sport. 2010;81(4):425-431. doi: 10.1080/02701367.2010.10599703 pmid: 21268466

8. Chauvel G, Wulf G, Maquestiaux F. Visual illusions can facilitate sport skill learning. Psychon Bull Rev. 2015;22(3):717-721. doi: 10.3758/s13423-014-0744-9 pmid: 25316049

9. Witt JK, Linkenauger SA, Proffitt DR. Get me out of this slump! Visual illusions improve sports performance. Psychol Sci. 2012;23(4):397-399. doi: 10.1177/0956797611428810 pmid: 22395130

10. Bargh JA, Chen M, Burrows L. Automaticity of social behavior: direct effects of trait construct and stereotype-activation on action. J Pers Soc Psychol. 1996;71(2):230-244. doi: 10.1037//00223514.71.2.230 pmid: 8765481 
11. Olver JM, Mooradian TA. Personality traits and personal values: a conceptual and empirical integration. Personal Ind Differ. 2003;35(1):109-125. doi: 10.1016/s0191-8869(02)00145-9

12. Kaefer A, Chiviacowsky S, Meira Cde M, Jr., Tani G. Self-controlled practice enhances motor learning in introverts and extroverts. Res $Q$ Exerc Sport. 2014;85(2):226-233. doi: 10.1080/02701367.2014.893051 pmid: 25098018

13. McCrae RR, Costa PT. A contemplated revision of the NEO Five-Factor Inventory. Personal Ind Differ 2004;36(3):587-596. doi: 10.1016/s0191-8869(03)00118-1

14. McKelvie SJ, Lemieux P, Stout D. Extraversion and neuroticism in contact athletes, no contact athletes and non-athletes: A research note. Athletic insight. 2003;5(3):19-27.

15. Bahmani B, Soukhtehzari S, Mazaherinezhad A, Sayyah M. Assessing Mental Skills of Student Athletes in a Colligate Sport Olympiad. Biosci Biotechnol Res Asia. 2015;12(Special-Edn2):527-531. doi: $10.13005 / \mathrm{bbra} / 2229$

16. Chavoshian M, Soukhtehzari S, Angoorani H, Rezaei M, Mansour S. Assessing and Comparing Mental Skills of Men Players' Positions in Volleyball Premier League Team of Iran. Sleep Hypn Int J. 2018;21(1):38-43. doi: 10.5350/Sleep.Hypn.2019.21.0170

17. Maia Bokums R, M. Meira Jr C, F. O. Neiva J, Oliveira T, Ferreira Maia J. Self-Controlled Feedback and Trait Anxiety in Motor Skill Acquisition. Psychol. 2012;03(05):406-409. doi: 10.4236/psych.2012.35057

18. Guadagnoli M, Lindquist K. Challenge Point Framework and Efficient Learning of Golf. Int J Sports Sci Coach. 2016;2(1_suppl):185-197. doi: 10.1260/174795407789705505

19. Moshirian Farahi M, Asghari Ebrahimabad MJ, Gorji A, Bigdeli I. Psychometric Features of the BigFive Personality Questionnaire for Children and Adolescence in Mashhad. Neurosci J Shefaye Khatam. 2019;7(1):13-22. doi: 10.29252/shefa.7.1.13

20. McAuley E, Duncan T, Tammen VV. Psychometric properties of the Intrinsic Motivation Inventory in a competitive sport setting: a confirmatory factor analysis. Res Q Exerc Sport. 1989;60(1):48-58. doi: 10.1080/02701367.1989.10607413 pmid: 2489825

21.Hosseini F, Norouzi E. The effect of neurofeedback training on self-talk and performance in elite and non-elite volleyball player. Med sport. 2017;70:000-000.

22. Hutchinson JC, Sherman T, Martinovic N, Tenenbaum G. The Effect of Manipulated Self-Efficacy on Perceived and Sustained Effort. J Appl Sport Psychol. 2008;20(4):457-472. doi: 10.1080/10413200802351151

23.Lewthwaite R, Wulf G. Social-comparative feedback affects motor skill learning. $Q J$ Exp Psychol (Hove). 2010;63(4):738-749. doi: 10.1080/17470210903111839 pmid: 19691002

24. Arjmand M, Badami R. Effects of normative feedback on learning volleyball serves vitality during exercise and interest to continue sports participation. Sport Psychol. 2018;3(1):9-22.

25. Stoate I, Wulf G, Lewthwaite R. Enhanced expectancies improve movement efficiency in runners. $J$ Sports Sci. 2012;30(8):815-823. doi: 10.1080/02640414.2012.671533 pmid: 22439657

26. Badhwar NK. The Milgram Experiments, Learned Helplessness, and Character Traits. J Ethics. 2009;13(2-3):257-289. doi: 10.1007/s10892-009-9052-4

27. Gelbrich K. Anger, frustration, and helplessness after service failure: coping strategies and effective informational support. J Acad Mark Sci. 2009;38(5):567-585. doi: 10.1007/s11747-009-0169-6

28. Mikulincer M, Caspy T. The conceptualization of helplessness: II. Laboratory correlates of the phenomenological definition of helplessness. Motiva Emot. 1986;10(3):279-294. doi: 10.1007/bf00992321

29. Harter S. The construction of the self: Developmental and sociocultural foundations: Guilford Publications; 2015.

30. McKenzie J. Three superfactors in the 16PF and their relation to Eysenck's P, E and N. Person Ind Differ. 1988;9(5):843-850. doi: 10.1016/0191-8869(88)90002-5

31. Gulliver A, Griffiths KM, Christensen H. Barriers and facilitators to mental health help-seeking for young elite athletes: a qualitative study. BMC Psychiatry. 2012;12:157. doi: 10.1186/1471-244X-12157 pmid: 23009161 